\title{
BANCO DE SEMENTES DO SOLO E SERAPILHEIRA ACUMULADA EM FLORESTA RESTAURADA ${ }^{1}$
}

Aurino Miranda Neto², Sebastião Venâncio Martins ${ }^{3}$, Kelly de Almeida Silva² e José Marinaldo Gleriani

\begin{abstract}
RESUMO - Este estudo teve por objetivo avaliar o banco de sementes do solo e a serapilheira acumulada em uma floresta restaurada por meio de plantio, com 40 anos, em Viçosa, MG. Foram alocadas 16 parcelas contíguas de 25 x 25 m, cobrindo toda a área da floresta (1 ha). Em cada parcela, foram coletadas cinco amostras de solo superficial $(0,30 \times 0,30 \times 0,05 \mathrm{~m})$ para avaliação do banco de sementes pelo método de germinação e uma amostra de $1,0 \mathrm{~m}^{2}$ de serapilheira para avaliação da serapilheira acumulada. Foi realizada a classificação dos indivíduos e espécies de plântulas registrados do banco de sementes quanto à categoria sucessional, síndrome de dispersão e hábito de vida. Foram registradas 5.555 plântulas pertencentes a 32 famílias e 93 espécies e um morfotipo que reuniu todas as trepadeiras. Registrou-se o predomínio de síndrome de dispersão zoocórica e, quanto ao hábito de vida, maior percentual de ervas, em nível de espécie (48,6\%) e de indivíduo (44,8\%). Entre as espécies arbustiva-arbóreas, observou-se maior percentual da categoria sucessional pioneira, em nível de espécie $(75,1 \%)$ e de indivíduo (85,1\%). A serapilheira média acumulada foi de $3.432 \mathrm{~kg} \mathrm{ha}^{-1}$, com a fração foliar representando 65\% e correlação significativa com a área basal $\left(p=0,031 ; \mathrm{R}^{2}=0,29\right)$ do estrato arbóreo. Os resultados indicam que o banco de sementes do solo da floresta restaurada, após 40 anos de sua implantação se assemelha, quanto as relações ecológicas, às áreas de floresta estacional semidecidual na mesma região e a outras áreas restauradas que também foram utilizados plantio de mudas.
\end{abstract}

Palavras-chaves: Restauração florestal; Indicadores de restauração ecológica; Síndromes de dispersão.

\section{SOIL SEED BANK AND ACCUMULATED LITTER IN RESTORED FOREST}

\begin{abstract}
This study aimed to evaluate the soil seed bank and accumulated litter in a restored forest through planting, aged 40, in Viçosa, MG. We allocated 16 contiguous plots of $25 \times 25 \mathrm{~m}$, covering the entire forest area (1 ha). In each plot, we collected five samples of surface soil $(0.30 \times 0.30 \times 0.05 \mathrm{~m})$ to evaluate the seed bank by germination method and a sample of $1.0 \mathrm{~m}^{2}$ litter for evaluation of accumulated litter. We performed the classification of individuals and species of seedlings of the seed bank as for successional category, dispersion syndrome and life form. 5,555 seedlings were recorded, belonging to 32 families and 93 species and morphotype which grouped all the vines. We recorded the predominance of zoochoric dispersion syndrome and, as for life form, a higher percentage of herbs, at the species level (48.6\%) and individuals (44.8\%). Among the shrub-arboreal species, we observed a higher percentage of successional category pioneer, species level (75.1\%) and individuals (85.1\%). The accumulated litter average was of 3,432 $\mathrm{kg} \mathrm{ha}^{-1}$, with the leaf fraction representing $65 \%$ and significant correlation with basal area $\left(p=0.031, R^{2}=0.29\right)$ of the tree stratum. The results indicate that the soil seed bank of forest restored after 40 years of its implementation is similar, as for ecological relations, to the areas of stational semidecidual forest in the same region and other restored areas that were also used for planting seedlings.
\end{abstract}

Keywords: Forest restoration; Indicators of ecological restoration; Dispersal syndromes.

\footnotetext{
${ }^{1}$ Recebido em 08.03.2012 aceito para publicação em 04.05.2014.

${ }^{2}$ Programa de Pós-Graduação em Ciência Florestal, Universidade Federal de Viçosa, UFV, Brasil. E-mail: <aur.neto@gmail.com> e < kellyalmeidaenf@yahoo.com.br>.

${ }^{3}$ LARF - Laboratório de Restauração Florestal, Departamento de Engenharia Florestal da Universidade Federal de Viçosa, Viçosa, MG, Brasil. E-mail: <venancio@ufv.br>.

${ }^{4}$ Departamento de Engenharia Florestal da Universidade Federal de Viçosa, Viçosa, MG, Brasil. E-mail: <gleriani@ufv.br>
} 


\section{INTRODUÇÃO}

Os ecossistemas florestais são redes complexas, resultado da interação dos fluxos de energia e ciclos de matéria entre as comunidades florestais e seus ambientes, estabelecendo um equilíbrio ecológico. Entretanto, as florestas têm sido degradadas fragmentadas e reduzidas ao longo do tempo, pelo aumento das atividades humanas. Isso torna necessário a restauração florestal de áreas degradadas, que é considerada uma das mais eficientes ferramentas de engenharia ecológica (LU et al., 2011).

A restauração florestal possui um papel de extrema importância pois reduz a perda de biodiversidade e a degradação dos recursos naturais (KAGEYAMA; GANDARA, 2005), tais como, o empobrecimento dos solos e a escassez de água ou a sua qualidade.

A implantação de um projeto de restauração florestal, por mais bem planejado e executado que seja, não garante que determinada área terá uma cobertura florestal autoregenerante e que desempenha as funções ecológicas esperadas (MARTINS, 2009). É imprescindível que se realize a avaliação e o monitoramento da área reflorestada em espaços regulares de tempo, a fim de evitar a ocorrência de imprevistos que possam prejudicar a restauração almejada para determinada área

A avaliação da restauração florestal pode ser baseada na análise da semelhança entre a área restaurada e outras áreas de referência, dentro do mesmo ecossistema, comparando a estrutura, função, composição e as relações dos processos ecológicos (HOBBS; NORTON, 1996). Portanto, ao avaliar uma floresta restaurada, são utilizados mecanismos vegetativos como a regeneração natural, chuva de sementes, banco de sementes do solo, abertura do dossel, produção e decomposição da serapilheira (MARTINS, 2009).

O processo de regeneração natural tem como fonte primária os diásporos que chegam na área através da chuva de sementes, que posteriormente formará o banco de sementes do solo (GROMBONE-GUARATINI; RODRIGUES, 2002). A avaliação do estoque de sementes no solo é importante na determinação da melhor estratégia de manejo a ser empregada na conservação ou recomposição de florestas nativas (GROMBONE- GUARATINI; RODRIGUES, 2002; SORREANO, 2002)enomonitoramento e avaliação de áreas restauradas, obtendo melhores diagnósticos quanto ao desempenho e sucesso da restauração de ecossistemas florestais (MARTINS, 2009).
A serapilheira é outro importante componente do ecossistema florestal. Ela apresenta entradas e saídas, ou seja, recebe o material (folhas, ramos, frutos, sementes, cascas e flores) por meio da vegetação e esse material é decomposto para suprimento de nutrientes e matéria orgânica para o solo e raízes (MARTINS, 2009). A quantificação da sua produção e decomposição é um dos indicadores utilizados na avaliação e monitoramento de florestas restauradas (ARATO et al., 2003; MARTINS, 2009). Estudos sobre a produção de serapilheira podem constituir uma ferramenta fundamental na indicação do estágio de conservação e regeneração de áreas restauradas (MOREIRA; SILVA, 2004).

Este estudo objetiva avaliar o banco de sementes do solo e a serapilheira acumulada de uma floresta restaurada por meio de plantio, após 40 anos de sua implantação, no município de Viçosa, MG. A serapilheira acumulada e as relações ecológicas (riqueza, abundância, estrutura, categoria sucessional, hábitos de vida e síndromes de dispersão) do banco de sementes da floresta estudada apresentam parâmetros semelhantes a outras áreas de floresta estacional semidecidual na mesma região e a outras áreas restauradas por meio de plantio?

\section{MATERIAL E MÉTODOS}

O estudo foi realizado em uma floresta restaurada por meio de reflorestamento heterogêneo (1,0 ha), com idade de 40 anos, situada no campus da Universidade Federal de Viçosa (UFV), município de Viçosa (2045’14"S e 42 45’53"O), Zona da Mata de Minas Gerais. A vegetação da área de estudo é resultante de um plantio de espécies nativas e exóticas, perfazendo um total de 485 indivíduos e 56 espécies, no espaçamento de 4,0 x 5,0 m, realizado entre os anos de 1968 e 1969. Anterior ao plantio, a área era coberta por um plantio de Eucalyptus sp. O seu entorno é composto por fragmentos florestais e pela rodovia MG-280. As espécies plantadas constituem 11,0\% de pioneiras, 35,0\% de secundária inicial, 21,0\% de secundária tardia e 33,0\% sem classificação.

O clima na região é do tipo Cwb (Köppen), mesotérmico com verões quentes e chuvosos e invernos frios e secos. A temperatura média anual é de $19,3^{\circ} \mathrm{C}$ e a precipitação pluviométrica média anual de 1.247 mm (ROCHA; FIALHO, 2010).

Foram alocadas na área 16 parcelas contíguas de 25 x 25m, cobrindo toda a área da floresta. No início de 2010, em cada parcela, foram coletadas de forma 
aleatória e por sorteio cinco amostras de solo, desprezando a serapilheira dura, com auxílio de um gabarito de madeira de $0,30 \times 0,30 \mathrm{~m}$, perfazendo um total de 80 amostras. Coletou-se a camada de solo superficial até uma profundidade de $5,0 \mathrm{~cm}$, colocando as amostras em sacos plásticos e transportadas para a casa de sombra do Viveiro de Pesquisas do Departamento de Engenharia Florestal na Universidade Federal de Viçosa. As amostras coletadas foram então transferidas para bandejas plásticas $(0,23 \times 0,36 \times 0,05$ $\mathrm{m}$ ) dispostas em uma bancada a 1,0 m de altura do piso, mantidas em ambiente isolado de possíveis contaminações por propágulos externos, pois foram cobertas por sombrite $50 \%$. Como controle, para verificação de possível contaminação, foram dispostas na bancada quatro bandejas com areia estéril. As amostras ficaram sob irrigação por aspersão, programada durante o período de seis meses.

As plântulas que emergiram em cada amostra foram contabilizadas quinzenalmente e identificadas até o táxon possível. As plântulas de trepadeiras foram apenas contadas e agrupadas em um único morfotipo devido à dificuldade para a identificação das espécies. Para as espécies não identificadas no viveiro, coletouse o material botânico para posterior comparação ao material depositado no herbário VIC da Universidade Federal de Viçosa, MG, consulta a especialistas e a literatura. As espécies foram separadas em famílias e tiveram os nomes científicos e seus respectivos autores atualizados pela base de dados do Missouri Botanical Garden, através do site www.tropicos.org, de acordo com o sistema do Angiosperm Phylogeny Group III (APG III, 2009).

Foram calculados os parâmetros fitossociológicos (MUELLER-DOMBOIS; ELLENBERG, 1974), o índice de diversidade de Shannon-Wiener (H') (MAGURRAN, 1988) e a equabilidade (J') (PIELOU, 1975), através do programa FITOPAC 2.1 (SHEPHERD, 2010).

As espécies amostradas foram classificadas quanto ao hábito de vida. Posteriormente, as espécies arbóreas e arbustivas foram separadas por categorias sucessionais de acordo com os critérios propostos por Budowski (1965) e adaptados por Gandolfi et al. (1995) para florestas semidecíduas brasileiras, sendo: pioneira, secundária inicial, secundária tardia e não classificada. Foram também separadas por síndromes de dispersão de propágulos em zoocóricas, anemocóricas e autocóricas (PIJL, 1982).
Foi coletada, no centro de cada parcela da floresta restaurada, com o auxílio de um gabarito de madeira, amostra de 1,0 $\mathrm{m}^{2}$ de serapilheira acumulada. Em laboratório, as amostras de serapilheira foram separadas em três grupos (folha, ramos, material reprodutivo), secas em estufa a $70^{\circ} \mathrm{C}$, por 24 horas e quantificadas a massa seca em balança de precisão.

Realizaram-se ajustes de regressões para verificar a relação entre a serapilheira acumulada e os parâmetros da estrutura da vegetação arbustivo-arbórea adulta presente nas parcelas (indivíduos arbustivo-arbóreos com circunferência a 1,30 m do solo, igual ou superior a $15 \mathrm{~cm}$ ), segundo Miranda Neto et al. (2012). Foram considerados a densidade de indivíduos, a altura média, a área basal e o índice de área foliar (IAF).

\section{RESULTADOS}

Foram amostradas 5.555 plântulas, pertencentes a 32 famílias, 68 gêneros e 93 espécies e um morfotipo que reuniu todas as trepadeiras (Tabela 1). Obteve-se densidade de 15.430 propágulos por $\mathrm{m}^{3}$, distribuída em 5.425 propágulos de ervas, 4.755 propágulos de arbustos, 4.667 propágulos de árvores, 503 propágulos de gramíneas e 80 propágulos de trepadeiras. Nas bandejas controle, com areia, não houve emergência de plântulas.

Com relação as famílias, destacaram-se Melastomataceae, Solanaceae, Asteraceae, Urticaceae e Plantaginaceae, perfazendo 75,2\% das plântulas amostradas. Melastomataceae compõe 41,5\% das plântulas amostradas, representada principalmente por Leandra niangaeformis Cogn., Leandra purpurascens (DC.) Cogn. e Miconia cinnamomifolia (DC.) Naudin, que juntas responderam por 38,3\% do total de plântulas amostradas e 92,2\% das plântulas pertencentes a família Melastomataceae.

Entre as espécies com maior número de plântulas amostradas, destaque entre cada hábito de vida para a arbórea Miconia cinnamomifolia, com 11,7\% do total, a arbustiva Leandra niangaeformis, com 15,6\%, a herbácea Solanum americanum Mill., com 8,5\% e a gramínea Paspalum paniculatum L., com 1\%.

O índice de diversidade de Shannon-Wiener ( $\left.\mathrm{H}^{\prime}\right)$ foi de 3,21 e o índice de equabilidade (J’) foi de 0,708.

Quanto ao hábito de vida, foram registradas 1.953 plântulas de 43 espécies herbáceas, 1.680 plântulas de 25 espécies arbóreas, 1.712 plântulas de 17 espécies

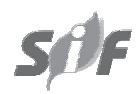

Revista Árvore, Viçosa-MG, v.38, n.4, p.609-620, 2014 


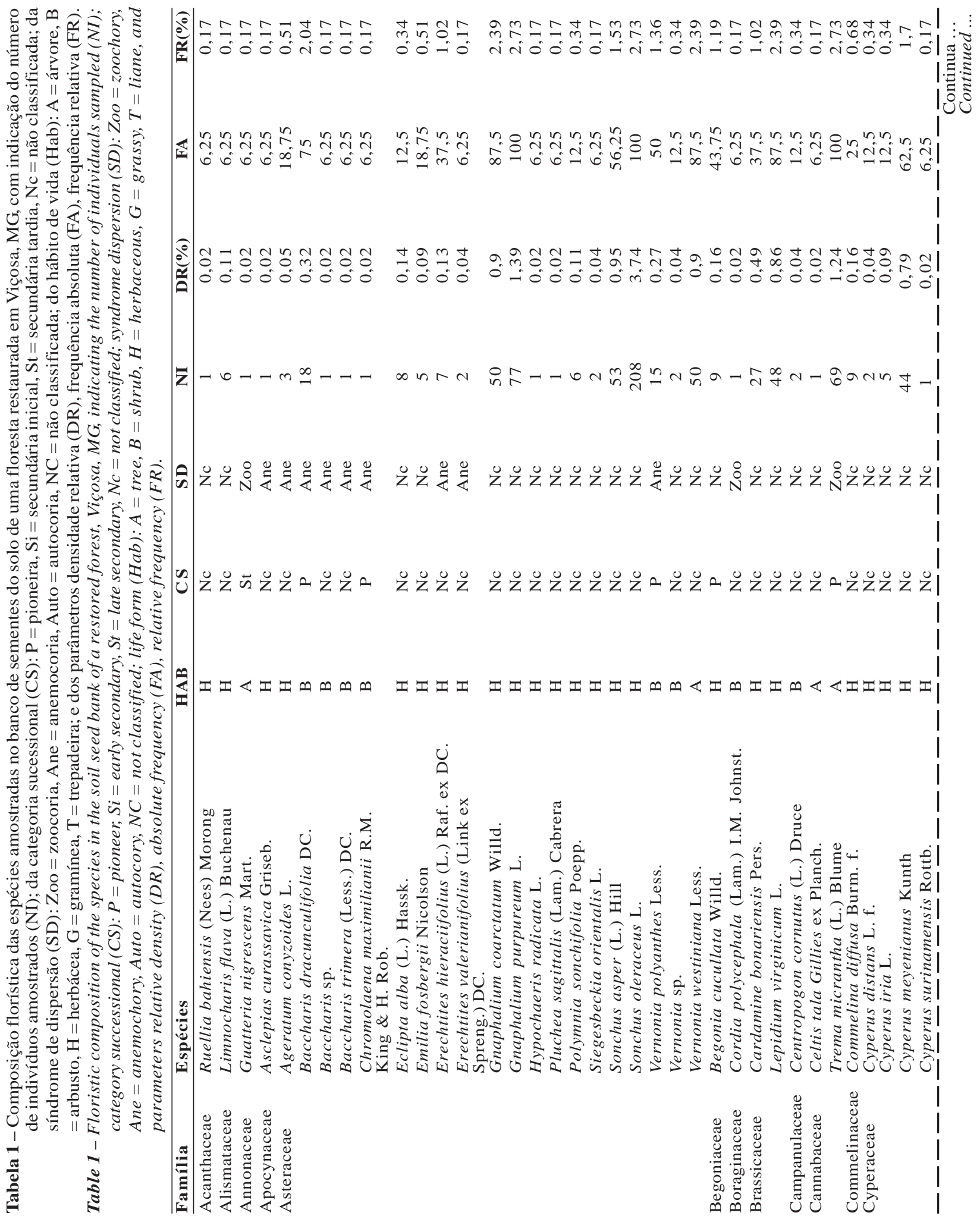




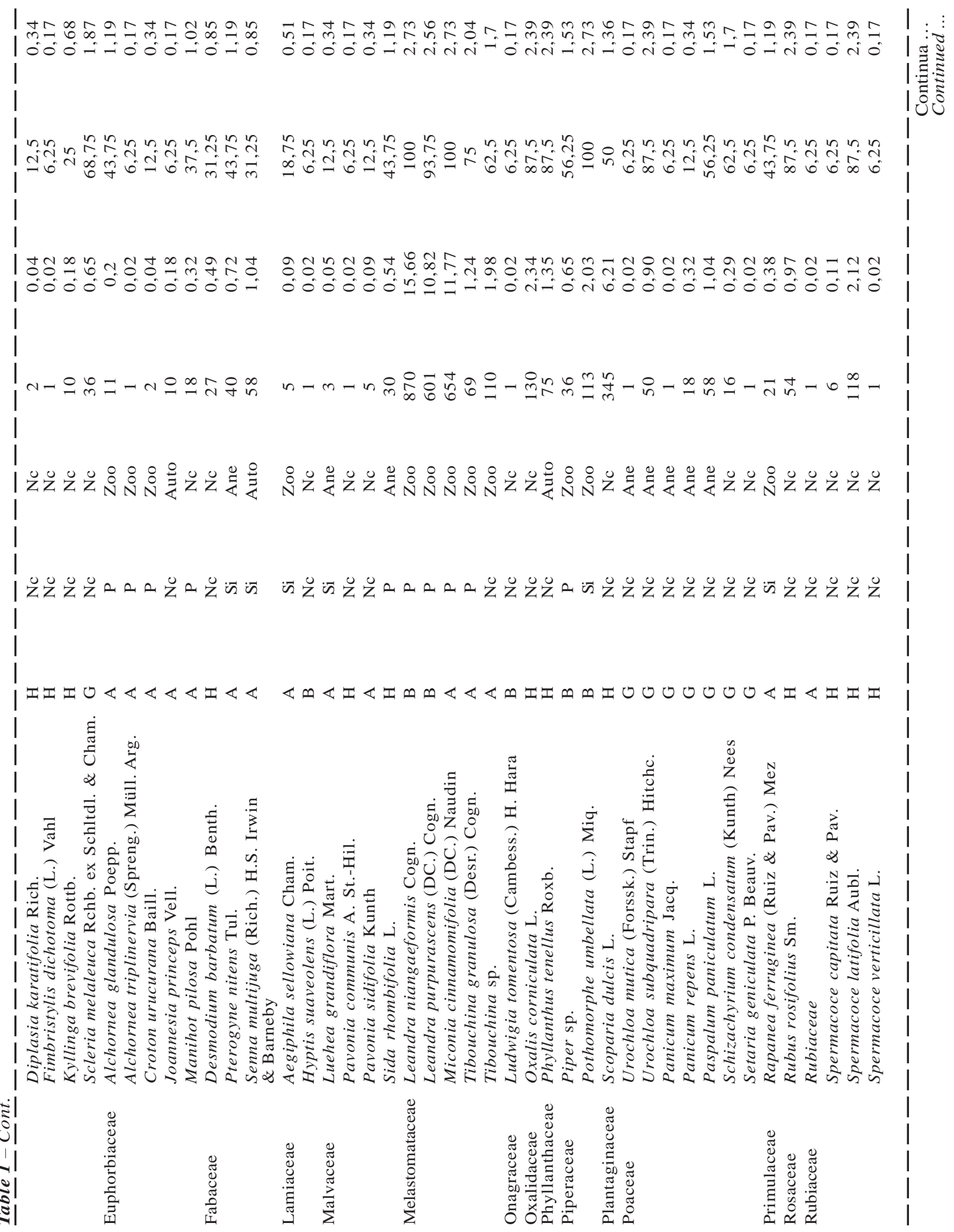




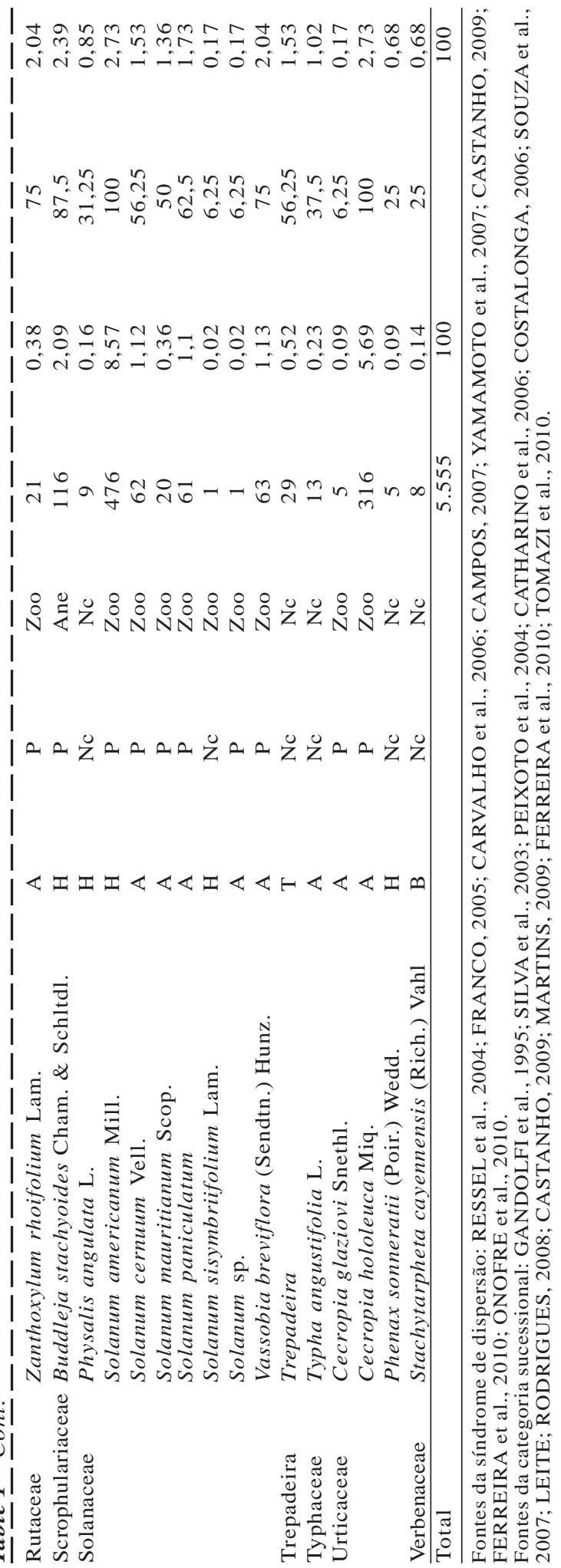

arbustivas, 181 plântulas de oito espécies de gramíneas e 29 plântulas de um morfotipo de trepadeiras (Figura 1). Entre as espécies arbóreas e arbustivas, foram registrados 21 espécies pioneiras, seis secundárias iniciais, uma secundária tardia e 14 não classificadas. Em nível de indivíduos, foram registradas 2.957 plântulas pioneiras, 240 secundárias iniciais, uma secundária tardia e 198 não classificadas (Figura 2).

Quanto à síndrome de dispersão foram registradas 24 espécies zoocóricas, 7 anemocóricas, 2 autocóricas e 9 não classificadas. Em nível de indivíduos, foram

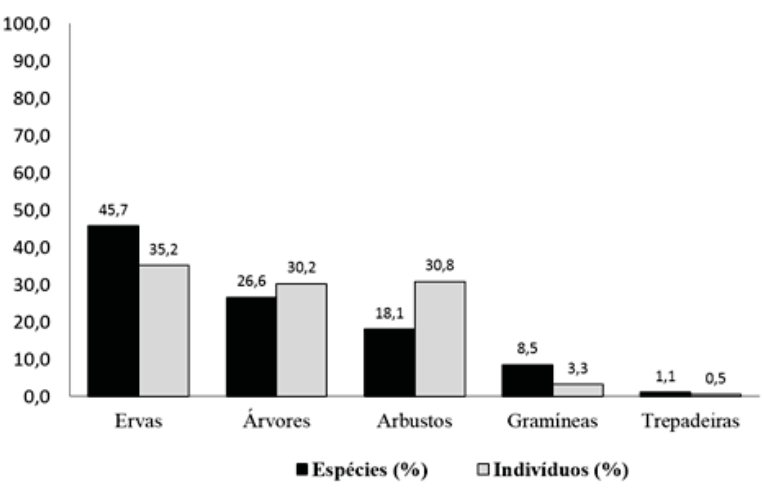

Figura 1 - Distribuição em porcentagem, em nível de espécies e indivíduos, para hábito de vida do banco de sementes do solo da floresta restaurada, Viçosa, MG.

Figure 1 -Distribution in percentage at the level of species and individuals, to life forms of the soil seed bank of the restored forest, Viçosa, MG.

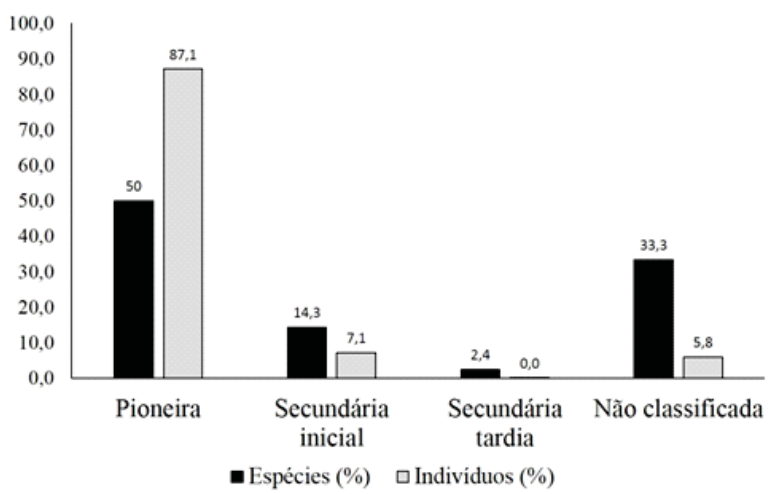

Figura 2 - Distribuição em porcentagem, em nível de espécies e indivíduos arbustivo-arbóreos, para a categoria sucessional do banco de sementes do solo da floresta restaurada, Viçosa, MG.

Figure 2-Distribution in percentage at the level of species and shrub-arboreal individuals, to successional category of the soil seed bank of the restored forest, Viçosa, MG. 
registrados 3.165 plântulas zoocóricas, 78 anemocóricas, 68 autocóricas e 81 não classificadas (Figura 3).

A serapilheira média acumulada foi de 343,2 \pm 225,3 $\mathrm{g} \mathrm{m}^{-2}$ (3.432 $\left.\pm 2.254 \mathrm{~kg} \mathrm{ha}^{-1}\right)$, distribuídos em 222,1 \pm 155,9 $\mathrm{g} \mathrm{m}^{-2}$ de folhas, 98,2 $\pm 55,4 \mathrm{~g} \mathrm{~m}^{-2}$ de ramos e 22,9 \pm 31,6 $\mathrm{g} \mathrm{m}^{-2}$ de material reprodutivo (semente, fruto, flor).

As análises de regressão indicaram que a serapilheira acumulada por parcela não apresentou correlação significativa com a densidade de indivíduos $(P=0,404$; $\left.\mathrm{R}^{2}=0,0502\right)$, com a altura média das árvores $(P=0,892$; $\left.\mathrm{R}^{2}=0,0014\right)$ e com o índice de área foliar $\left(P=0,089 ; \mathrm{R}^{2}\right.$ $=0,1925)$. Entretanto, a serapilheira acumulada apresentou correlação significativa com a área basal $\left(P=0,031\right.$; $\mathrm{R}^{2}$ $=0,2908$ ) dos indivíduos do estrato arbóreo (Figura 4).

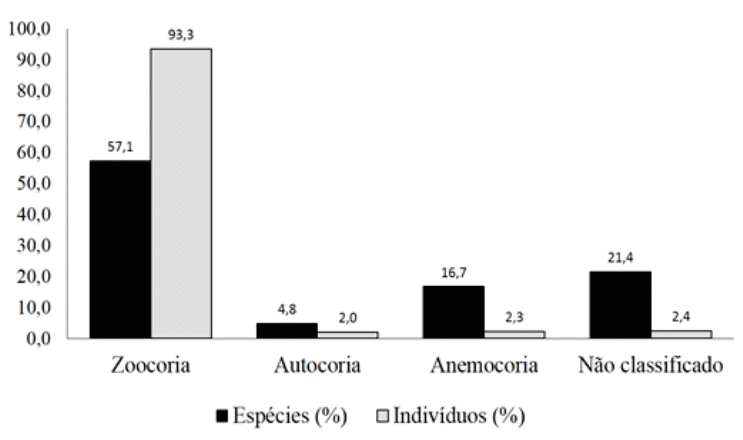

Figura 3 - Distribuição em porcentagem, em nível de espécies e indivíduos, para síndrome de dispersão do banco de sementes do solo da floresta restaurada, Viçosa, MG.

Figure 3 -Distribution in percentage at the level of species and individuals, to dispersion syndrome of the soil seed bank of the restored forest, Viçosa, MG.

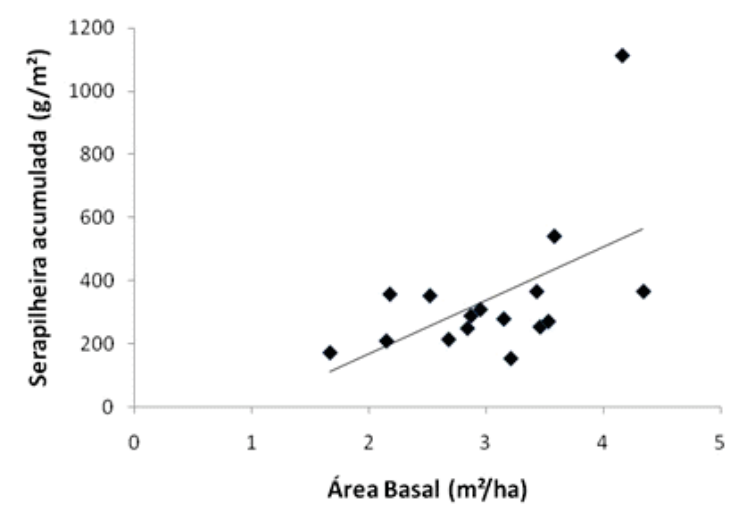

Figura 4 - Correlação entre serapilheira acumulada $\left(\mathrm{g} \mathrm{m}^{-2}\right)$ e área basal $\left(\mathrm{m}^{2} \mathrm{ha}^{-1}\right)$ dos indivíduos do estrato arbustivo-arbóreo adulto.

Figure 4-Correlation between accumulated litter $\left(\mathrm{g} \mathrm{m}^{-2}\right)$ and basal area $\left(\mathrm{m}^{2} \mathrm{ha}^{-1}\right)$ of individuals of adult shrub-arboreal stratum.

\section{DISCUSSÃO}

A densidade de propágulos foi inferior a diversos estudos sobre banco de sementes em floresta estacional semidecidual na região Zona da Mata de Minas Gerais (BATISTA NETO et al., 2007; MARTINS et al., 2008; FRANCO et al., 2012), porém superior aos estudos de Costalonga (2006) e Braga et al. (2008). Essa variação nos valores dos respectivos trabalhos diante do presente estudo pode estar relacionado com os diferentes tamanhos e quantidades de unidades amostrais utilizados. Além disso, a densidade do banco de sementes, geralmente, ocorre com variação entre um local e outro, com tendência a apresentar maior quantidade em florestas secundárias, onde a densidade de sementes pioneiras é maior devido apresentar dormência e isso permitir a permanência mais longa no solo (BAIDER et al., 2001; DALLING, 2002).

Em comparação com áreas restauradas por meio de plantio, Sorreano (2002) encontrou, em floresta com nove anos de restauração, valor superior ao presente estudo, enquanto que nas florestas com 46, nove e seis anos de restauração, os valores foram inferiores. Siqueira (2002) encontrou, em floresta com 14 anos de restauração, valor superior e em florestas com 10 e 14 anos de restauração, valores abaixos do presente trabalho. Os menores valores encontrados por Siqueira (2002) e Sorreano (2002) possivelmente estão associados a ausência de matriz florestal no entorno das áreas restauradas estudadas, acarretando diminuição da entrada de sementes no solo. Isso evidencia bons resultados alcançados para a floresta restaurada em Viçosa, MG, já que esta floresta está inserida em uma matriz florestal e possivelmente não há barreiras aos dispersores, facilitando a chegada de propágulos.

O índice de diversidade de Shannon e equabilidade encontrados mostram que a área possui uma diversidade média e se apresenta floristicamente heterogênea com baixa dominância ecológica para os padrões de floresta estacional semidecidual. Segundo Meira Neto e Martins (2003), nas florestas estacionais semidecíduais, no estado de Minas Gerais, o índice de diversidade varia entre 3,2 e 4,2 e a equabilidade, entre 0,73 e 0,88. Braga et al. (2008) em estudo de banco de sementes em floresta estacional semidecidual na região de Viçosa, MG obteve índice de diversidade inferior ao presente estudo. Entretanto, estes autores analisaram apenas espécies arbustiva-arbóreas.

Revista Árvore, Viçosa-MG, v.38, n.4, p.609-620, 2014 
As famílias com maior densidade de indivíduos, também foram ressaltadas em outros estudos realizados em fragmentos florestais da região da Zona da Mata de Minas Gerais (COSTALONGA, 2006; BATISTANETO et al., 2007; BRAGA et al., 2008; MARTINS et al., 2008; FRANCO et al., 2012). Melastomataceae, família em maior destaque, é a sexta maior família de Angiospermas no Brasil, com 68 gêneros e mais de 1.500 espécies, distribuídas em todo território brasileiro e quase todas as formações vegetacionais. São encontradas em diversos hábitos de vida, permitindo ocupar ambientes distintos e diversificados (ROMERO; MARTINS, 2002).

Quanto ao hábito, a maior porcentagem dos indivíduos verificada foi de herbáceas (35\%), porém um valor bastante próximo ao de arbustivos e arbóreos e muito inferior ao encontrado nos estudos realizados por Martins et al. (2008) para floresta secundária em área degradada por mineração de caulim, com 82,2\% de indivíduos herbáceos, Batista Neto et al., (2007) com 59,1\% e Costalonga (2006) com 85,0\%, todos na Zona da Mata mineira, e em florestas restauradas na região Sudeste, com, 62,5\% dos indivíduos em uma floresta restaurada com 46 anos, 86,0\% em uma floresta com nove anos e 86,5\% em uma floresta com seis anos (SORREANO, 2002); 82,2\% dos indivíduos de uma floresta restaurada com 10 anos, 81,1\% dos indivíduos de uma floresta restaurada com 14 anos (SIQUEIRA, 2002).

A predominância de herbáceas em florestas restauradas, provavelmente ocorre em razão do histórico de perturbação, pois estas áreas foram utilizadas no passado para atividades agrícolas. A maior disponibilidade de espaço e de luminosidade favorece as espécies herbáceas ruderais e muitas espécies de gramíneas. Como as ervas são dotadas, em geral, de sementes muito pequenas, com baixo metabolismo e produzem muitas sementes, elas formam um extenso banco de sementes viáveis e longevas que germinam quando as condições ambientais se tornam favoráveis. Entretanto, o número de indivíduos arbóreos e arbustivos do presente estudo soma $61,05 \%$ do total registrado, ou seja, apesar das ervas constituírem a maior quantidade de indivíduos, a sua representatividade comparada com a soma de indivíduos arbóreo-arbustivo é baixa.

A maior proporção de espécies e de indivíduos arbustivo-arbóreos pioneiros corrobora os diversos trabalhos com banco de sementes na Zona da Mata de Minas Gerais (COSTALONGA, 2006; BATISTA
NETO et al., 2007; BRAGA et al., 2008; RODRIGUES et al., 2010; MIRANDA NETO et al., 2010; FRANCO et al., 2012) e em outras formações florestais no Brasil (BAIDER et al., 1999; ARAÚJO et al., 2001; MONACO et al., 2003).

As espécies pioneiras são predominantes no banco de sementes persistente do solo, viáveis a germinação, por longo tempo, até encontrar condições adequadas a sua germinação (BAZZAZ; PICKETT, 1980; ARAUJO et al., 2001). Como a proporção de espécies pioneiras utilizadas no plantio foi baixa, o predomínio de espécies pioneiras no banco de sementes indica que a área recebe propágulos oriundos de matriz florestal do entorno, o que pode possibilitar o estabelecimento de novas espécies na área. O maior fragmento florestal vizinho é a Mata da Silvicultura, que possui 17 ha, resultante de regeneração natural desde 1936, quando foi adquirida e protegida de cortes e extração de madeira pela Universidade Federal de Viçosa (MARISCAL-FLORES, 1993). Com isso, há o aumento da riqueza florística e da biodiversidade local, beneficiada pela Mata da Silvicultura.

A baixa proporção de espécies secundárias tardias sugere estratégia de perpetuação e regeneração baseadas na formação de banco de plântulas, pois suas sementes apresentam baixa viabilidade, alto grau de predação e dificuldade de enterramento e permanência no solo (PIÑA-RODRIGUES et al., 1990).

Encontrou-se predomínio de espécies e indivíduos zoocóricos, assim como nos estudos de Baider et al. (1999) e Franco et al. (2012). A dispersão zoocórica é muito importante na manutenção e aumento da fauna dispersora de sementes no início da formação de uma floresta (FRANCO et al., 2012), alavancando o processo de regeneração. As plantas investem em variados recursos como arilos e polpas, atraindo diversos animais que irão dispersar as sementes por uma área maior de abrangência dentro e ao redor da floresta, auxiliando a sucessão secundária (MARTINS, 2009).

A serapilheira acumulada ( $3.432 \mathrm{~kg} \mathrm{ha}^{-1}$ ) foi inferior ao encontrado em estudos em floresta estacional semidecidual em Minas Gerais (WERNECK et al, 2001; PINTO et al., 2008). Estes trabalhos foram desenvolvidos em trechos de florestas conservados e sem relatos de perturbações por pelo menos nos últimos trinta anos, contribuindo para uma boa formação estrutural da floresta e, consequente, maior produção de serapilheira. 
Em uma área reflorestada com espécies nativas e exóticas, com seis anos após o plantio utilizando 60 espécies no estado de São Paulo, obteve-se uma produção de serapilheira de 407,73 $\mathrm{kg} \mathrm{ha}^{-1}$ na estação úmida e 647,56 kg ha-1 na estação seca (MOREIRA; SILVA, 2004), valores bem abaixo do encontrando no presente estudo. Já para uma floresta restaurada com mais de 100 anos de idade (Floresta da Tijuca, RJ), a produção de serapilheira (8.900 $\mathrm{kg} \mathrm{ha}^{-1}$ ) foi superior (OLIVEIRA; LACERDA, 1993). Os estudos mostram uma relação diretamente proporcional entre a produção de serapilheira e a idade dos reflorestamentos.

A maior proporção encontrada para a fração foliar corrobora com diversos trabalhos em florestas estacionais semideciduais (MARTINS; RODRIGUES, 1999; WERNECK et al., 2001; ARATO et al., 2003; PINTO et al., 2008). As folhas da serapilheira são as responsáveis pela maior transferência anual de nutrientes ao solo (SELLE, 2007).

A relação significativa entre serapilheira acumulada e área basal da vegetação, demonstra que a serapilheira acumulada aumenta com a biomassa da floresta. As parcelas contendo indivíduos com diâmetros maiores, pertencentes ao estrato arbóreo, apresentaram tendência à maior quantidade de serapilheira acumulada.

\section{CONCLUSÕES}

O banco de sementes do solo da floresta restaurada, após 40 anos de sua implantação se assemelha, às áreas de floresta estacional semidecidual na mesma região e a outras áreas restauradas por meio de plantio.

\section{AGRADECIMENTOS}

À CAPES pela bolsa de Doutorado do primeiro autor e ao CNPq pelas bolsas de Produtividade em Pesquisa do segundo autor e de Doutorado do terceiro autor.

\section{REFERÊNCIAS}

APG III - Angiosperm Phylogeny Group III. An update of the Angiosperm Phylogeny Group classification for the orders and families of flowering plants. Botanical Journal of the Linnean Society, v.161, n.2, p.105-121, 2009.

ARATO, H. D.; MARTINS, S. V.; FERRARI, S. H. Produção e decomposição de serapilheira em um sistema agroflorestal implantado para recuperação de áreas degradadas em Viçosa-MG. Revista Árvore, v.27, n.5, p.715-721, 2003.
ARAÚJO, M. M. et al. Densidade e composição florística do banco de sementes do solo de florestas sucessionais na região do Baixo Rio Guamá, Amazônia Oriental. Scientia

Forestalis, n. 59, p.115-130, 2001.

BAIDER, C.; TABARELLI, M.; MANTOVANI, W. O banco de sementes de um trecho de uma Floresta Atlântica Montana (São Paulo - Brasil). Revista Brasileira de Biologia, v.59, n.2, p.319-328, 1999.

BAIDER, C.; TABARELLI, M.; MANTOVANI, W. The soil seed bank during Atlantic forest regeneration in Southeast Brazil. Revista Brasileira de Biologia, v.61, n.1, p. 35-44, 2001.

BATISTA NETO, J. P. et al. Banco de sementes do solo de uma Floresta Estacional Semidecidual, em Viçosa, Minas Gerais. Ciência Florestal, v.17, n.4, p.311-320, 2007.

BAZZAZ, F. A.; PICKETT, S. T. A. Physiological ecology of tropical succession: a comparative review. Annual Review on Ecology and Systematics, v.11, p.287-310, 1980.

BRAGA, A. J. T.; GRIFFITH, J. J.; PAIVA, H. N.; MEIRA NETO, J. A. A. Composição do banco de sementes de uma floresta semidecidual secundária considerando o seu potencial de uso para recuperação ambiental. Revista Árvore, v. 32, n. 6, p. 1089-1098, 2008.

BUDOWSKI, G. Distribution of tropical american rain forest species in the light of successional processes. Turrialba, v.15, n.1, p.40-42, 1965

CAMPOS, E. P. Fenologia e chuva de sementes em floresta estacional semidecidual no município de Viçosa, Minas Gerais, Brasil. 2007. 50f. Tese (Doutorado em Botânica) - Universidade Federal de Viçosa, Viçosa, MG, 2007.

CARVALHO, F. A.; NASCIMENTO, M. T.; BRAGA, J. M. A. Composição e riqueza florística do componente arbóreo da Floresta Atlântica Submontana na região de Imbaú, município de Silva Jardim, RJ. Acta Botanica Brasilica, v.20, n.3, p.727-740, 2006.

Revista Árvore, Viçosa-MG, v.38, n.4, p.609-620, 2014 
CAStAnHO, G. G. Avaliação de dois trechos de uma Floresta Estacional Semidecidual restaurada por meio de plantio, com 18 e 20 anos, no Sudeste do Brasil. 2009. 111f. Dissertação (Mestrado em Recursos Florestais) - Escola Superior de Agricultura “Luiz de Queiroz” - Universidade de São Paulo, Piracicaba, 2009.

CATHARINO, E. L. M. et al. Aspectos da composição e diversidade do componente arbóreo das florestas da Reserva Florestal do Morro Grande, Cotia, SP. Biota Neotropica, v.6, n.2, p.1-28, 2006.

CostalongA, S. R. Banco de sementes em áreas contíguas de pastagem degradada, plantio de eucalipto e floresta natural, em Paula Cândido - MG. 2006. 126f. Dissertação (Mestrado em Ciência Florestal) Universidade Federal de Viçosa, Viçosa, MG, 2006.

DALLING, J. W. Ecología de semillas. In: GUARIGUATA, M. R.; KATTAN, G. H. (Ed.). Ecología y conservación de bosquesneotropicales. Cartago: Libro Universitario Regional, 2002. p. 345-375.

FERREIRA, W. C. et al. Regeneração natural como indicador de recuperação de área degradada a jusante da Usina Hidrelétrica de Camargos, MG. Revista Árvore, v.34, n.4, p.651-660, 2010.

FRANCO, B.K.S. Análise da regeneração natural e do banco de sementes em um trecho de floresta Estacional Semidecidual no campus da Universidade Federal de Viçosa, MG. 2005. 72f. Dissertação (Mestrado em Ciência Florestal) - Universidade Federal de Viçosa, Viçosa, MG, 2005.

FRANCO, B. K. S. et al. Densidade e composição florística do banco de sementes de um trecho de floresta estacional semidecidual no campus da Universidade Federal de Viçosa, Viçosa, MG.

Revista Árvore, v.36, n.3, p.423-432, 2012.

GANDOLFI, S.; LEITÃO FILHO, H. F.; BEZERRA, C. L. F. Levantamento florístico e caráter sucessional das espécies arbustivo-arbóreas de uma floresta semidecídua no município de Guarulhos, SP. Revista Brasileira de Biololgia, v.55, n.4, p.753-767, 1995.
GROMBONE-GUARATINI, M. T.; RODRIGUES, $\mathrm{R}$. R. Seed bank and seed rain in a seasonal semi-deciduous forest in south-eastern Brazil. Journal of Tropical Ecology, v.18, p.759-774, 2002.

HOBBS, R. J.; NORTON, D. A. Towards a conceptual framework for restoration ecology. Restoration Ecology, v.4, n.2, p.93-110, 1996.

KAGEYAMA, P. Y.; GANDARA, F. B. Resultados do programa de restauração com espécies arbóreas nativas do convênio ESALQ/USP e CESP. In: GALVÃO, A. P. M.; PORFÍRIO-DA-SILVA, V. (Ed.). Restauração florestal: fundamentos e estudos de caso. Colombo: 2005. p. 47-58.

LEITE, E. C.; RODRIGUES, R. R. Fitossociologia e caracterização sucessional de um fragmento de floresta estacional no sudeste do Brasil. Revista Árvore, v.32, n.3, p.583-595, 2008.

LU, H. F. et al. Emergy and eco-exergy evaluation of four forest restoration modes in southeast China. Ecological Engineering, v.37, n.2, p.277-285, 2011.

MAGURRAN, A. E. Ecological diversity and its measurement. London: Croom Hell 1988. 179 p.

MARISCAL-FLORES, E. J. Potencial produtivo e alternativas de manejo sustentável de um fragmento de Mata Atlântica secundária, Município de Viçosa, Minas Gerais. 1993. 165f.

Dissertação (Mestrado em Ciência Florestal) Universidade Federal de Viçosa, Viçosa, MG, 1993.

MARTINS, S. V. Recuperação de áreas degradadas: ações em áreas de preservação permanente, voçorocas, taludes rodoviários e de mineração. Viçosa, MG: Aprenda Fácil, 2009. 270p.

MARTINS, S. V. et al. Banco de sementes como indicador de restauração de uma área degradada por mineração de caulim em Brás Pires, MG. Revista Árvore, v.32, n.6, p.1081-1088, 2008.

MARTINS, S. V.; RODRIGUES, R. R. Produção de serapilheira em clareiras de uma floresta estacional semidecidual no município de Campinas, SP. Revista Brasileira de Botânica, v.22, n.3, p.405-412, 1999. 
MEIRA NETO, J. A. A.; MARTINS, F. R. Estrutura do sub-bosque herbáceo-arbustivo da mata da silvicultura, uma floresta estacional semidecidual no município de Viçosa/MG. Revista Árvore, v.27, n.4, p.459-471, 2003.

MIRANDA NETO, A. et al. Transposição do banco de sementes do solo como metodologia de restauração florestal de pastagem abandonada em Viçosa, MG. Revista Árvore, v.34, n.6, p.1035-1043, 2010.

MIRANDA NETO, A. et al. Florística e estrutura do estrato arbustivo-arbóreo de uma floresta restaurada com 40 anos, Viçosa, MG. Revista Árvore, v.36, n.5, p.869-878, 2012.

MONACO, L. M.; MESQUITA, R. C. G.; WILLIAMSON, G. B. Banco de sementes de uma floresta secundária amazônica dominada por Vismia. Acta Amazônica, v.33, n.1, p.41-52, 2003.

MOREIRA, P. R.; SILVA, O. A. Produção de serapilheira em área reflorestada. Revista Árvore, v.28, n.1, p. 49-59, 2004.

MUELLER-DOMBOIS, D.; ELLENBERG, H. Aims and methods of vegetation ecology. New York: John Wiley \& Sons, 1974. 547p.

OLIVEIRA, R. R.; LACERDA, L. D. Produção e composição química da serapilheira na floresta da Tijuca (RJ). Revista Brasileira de Botânica, v.16, n.1, p.93-99, 1993.

ONOFRE, F. F.; ENGEL, V. L.; CASSOLA, H. Regeneração natural de espécies da Mata Atlântica em sub-bosque de Eucalyptus saligna Smith. em uma antiga unidade de produção florestal no Parque das Neblinas, Bertioga, SP. Scientia Forestalis, v.38, n.85, p.39-52, 2010.

PEIXOTO, G. L. et al. Composição florística do componente arbóreo de um trecho de Floresta Atlântica na Área de Proteção Ambiental da Serra da Capoeira Grande, Rio de Janeiro, RJ, Brasil.

Acta Botanica Brasilica, v.18, n.1, p.151160, 2004.

PIELOU, E. C. Ecological diversity. New York: Jonhon Willey, 1975. 165p.

van der PIJL, L.. Principles of dispersal in higher plants. 3. ed. New York: SpringerVerlag, 1982. 214p.
PIÑA-RODRIGUES, F. C. M.; COSTA, L. G. S.; REIS, A. Estratégias de estabelecimento de espécies arbóreas e o manejo de florestas tropicais. In: CONGRESSO FLORESTAL BRASILEIRO, 6., 1990, Campos do Jordão. Anais... Campos do Jordão: SBS-SBEF, 1990. p.676-684.

PINTO, S. I. C. et al. Influence of environmental variables on the shrub and tree species distribution in two Semideciduous Forest sites in Viçosa, Minas Gerais, Brazil. Revista Biologia Tropical, v.56, n.3, p.1557-1569, 2008.

RESSEL, K. et al. Ecologia morfofuncional de plântulas de espécies arbóreas da Estação Ecológica do Panga, Uberlândia, Minas Gerais. Revista Brasileira de Botânica, v.27, n.2, p.311-323, 2004.

ROCHA, V. M.; FIALHO, E. S. Uso da terra e suas implicações na variação termohigrométrica ao longo de um transeto campo-cidade no município de Viçosa-MG. Revista de Ciencias Humanas, v.10, n.1, p.64-77, 2010.

RODRIGUES, B. D.; MARTINS, S. V.; LEITE, H. G. Avaliação do potencial da transposição da serapilheira e do banco de sementes do solo para restauração florestal em áreas degradadas. Revista Árvore, v.34, n.1, p.65-73, 2010.

ROMERO, R.; MARTINS, A. B. Melastomataceae do Parque Nacional da Serra da Canastra, Minas Gerais, Brasil. Revista Brasileira de Botânica, v.25, n.1, p.19-24, 2002.

SELLE, G. L. Ciclagem de nutrientes em ecossistemas florestais. Bioscience Journal, v.23, n.4, p.29-39, 2007.

SHEPHERD, G. J. Fitopac 2.1 - Campinas, Departamento de Botânica, Universidade Estadual de Campinas, 2010.

SILVA, A. F. et al. Composição florística e grupos ecológicos das espécies de um trecho de floresta semidecídua submontana da Fazenda São Geraldo, Viçosa-MG. Revista Árvore, v.27, n.3, p.311-319, 2003.

Revista Árvore, Viçosa-MG, v.38, n.4, p.609-620, 2014 
SIQUEIRA, L. P. Monitoramento de áreas restauradas no interior do estado de São Paulo, Brasil. 2002. 116f. Dissertação (Mestrado em Recursos Floretais) - Escola Superior de Agricultura "Luiz de Queiroz", Universidade de São Paulo, Piracicaba, 2002.

SORREANO, M. C. M. Avaliação de aspectos da dinâmica de florestas restauradas, com diferentes idades. 2002. 145f.

Dissertação (Mestrado em Recursos Floretais) Escola Superior de Agricultura “Luiz de Queiroz”, Universidade de São Paulo, Piracicaba, 2002.

SOUZA, P. B. et al. Florística e estrutura da vegetação arbustivo-arbórea do sub-bosque de um povoamento de Eucalyptus grandis W. Hill ex Maiden em Viçosa, MG, Brasil. Revista Árvore, v.31, n.3, p.533-543, 2007.
TOMAZI, A. L.; ZIMMERMANN, C. E.; LAPS, R. R. Poleiros artificiais como modelo de nucleação para restauração de ambientes ciliares: caracterização da chuva de sementes e regeneração natural. Biotemas, v.23, n.3, p.125-135, 2010.

WERNECK, M. S.; PEDRALLI, G.; GIESEKE, L. F. Produção de serapilheira em trechos de uma floresta semidecídua com diferentes graus de perturbação na Estação Ecológica do Tripuí, Ouro Preto, MG. Revista Brasileira de Botânica, v.24, n.2, p.195-198, 2001.

YAMAMOTO, L. F.; KINOSHITA, L. S.; MARTINS, F. R. Síndromes de polinização e de dispersão em fragmentos da Floresta Estacional Semidecídua Montana, SP, Brasil. Acta Botanica Brasilica, v.21, n.3, p.553-573, 2007. 